\title{
A Current Study of Sedimentation, Bay of Fundy
}

$$
\text { by DONALD I. P. SWIFT }
$$

I and students of the Geology Department, DALHOUSIE UNIVERSITY, are presently studying Holocene sedimentation in the Bay of Fundy. Work to date has centered on the Minas Basin, one of the two eastward extensions of Fundy. The Basin, 60 by 20 miles with a 40 foot tide range, is a natural laboratory for the study of high and low energy tidal sedimentation. Specific problems include:

1. Microtopography, topography, and 3-dimensiona 1 aspects of tide generated sand bodies, and the relationship of these features to the tidal regimen.

2. Development of tide flats and marshes. These marginal deposits contain a record of the post-Pleistocene sea level rise, and shed light on the mechanisms of transgressive sedimentation.

During the spring and summer of 1965 , field work will be expanded to include sedimentary reconnaissance of the rest of the Fundy area. Tidal sedimentation will be studied in Fundy proper, and in its northeastern extension, Chignecto Bay. The floor of the Bay of Fundy will be examined in order to determine the extent to which the sediments have adjusted to post-Pleistocene conditions.

\section{Communications}

SWIFT, D.J.P., 1964, Sedimentary reconnaissance of the Minas Basin, Nova Scotia (oral report): Coastal Research Group 1964 meeting, Miami.

SWIFT, D.J.P., 1965, Sedimentary facies of the Minas Basin, Nova Scotia (abstract):Trans. Nova Scotia Institute of Science (in press)。 